\title{
Ectopic extra-nodal in situ follicular neoplasia (ISFN)
}

\author{
Luca Roncati $^{1} \cdot$ Antonio Maiorana $^{1}$
}

Received: 28 August 2016/Accepted: 29 August 2016/Published online: 22 September 2016

(C) Springer-Verlag Berlin Heidelberg 2016

Dear Editor,

In situ follicular neoplasia (ISFN) is a rare WHOrecognized entity, which manifests in architecturally normal lymph nodes or other lymphoid tissues with one or more bcl2-positive follicular germinal centers suggestive of mature B cell follicular lymphoma (FL) [1]. We would like to bring attention to the first documented case in the literature of ectopic tonsil tissue partially involved by ISFN. One year ago, a 36-year-old woman underwent treatment for a pre-invasive endometrial endometrioid carcinoma, a well-known non-lymphoid malignancy. In order not to jeopardize the patient's fertility, hormonal treatment was adopted based on medroxyprogesterone acetate. The ectopic tonsil was extracted from the left Eustachian tube, since the patient complained of persistent auditory disturbance. Blood tests showed no significant abnormalities. Subsequent investigations revealed no occult FL (the patient is currently in follow-up). Given the uniqueness of this case, during the diagnostic phase, we performed the entire immunohistochemical panel for FL, including immunoglobulins of lymphocyte surface (IgG, IgM). In addition to germinal center immunopositivity for bcl2, bcl6, CD10, CD20, and CD23, a monotypic expression for IgM was detected

Luca Roncati

emailmedical@gmail.com

1 Department of Diagnostic and Clinical Medicine and of Public Health, Division of Pathology, University of Modena and Reggio Emilia, Policlinico Hospital, I-41124, Modena, MO, Italy
(Fig. 1), exactly as would be observable in the course of overt FL $[2,3]$. The fluorescence in situ hybridization revealed the IgH/BCL2-t(14;18)(q32;q21) translocation, while the search for EBV antigens (EBER probe) resulted negative [4]. In challenging cases such as these, diagnosis should be performed by an expert hemolymphopathologist with immunohistochemical support. This is because ISFN entails four possible scenarios. (I) The patient may be affected by an underlying FL (near the site or elsewhere), the observed phenomenon being the colonization of pre-existing follicles by neoplastic germinal center cells [5]. (II) The patient may, in time, develop an overt FL, the observed changes being the expression of a pre-malignant condition [6]. (III) For the rest of the patient's life, no sign of progress towards FL may be apparent, and no sure explanation for the condition can be advanced [7]. (IV) The patient is affected by non-lymphoid malignancies [8]. For all the above reasons, ISFN diagnosis requires detailed analysis in the histopathological report, which should include precise indications for the patient's clinical management. It should also include an in-depth immunohistochemical description which assesses the presence of immunoglobulins of lymphocyte surface. In previous series, identified clonality was not univocally correlated with increased risk of overt FL [9]. The detection of concurrent alterations in germinal centers (bcl2 immunopositivity and restricted Ig expression) and bcl 2 positivity alone should likewise not lead physicians to premature FL diagnosis, but a careful examination of the patient is mandatory. The above data could be of particular relevance to patients previously affected by malignancies and who underwent radio-/chemotherapy or hormone therapy. 




A
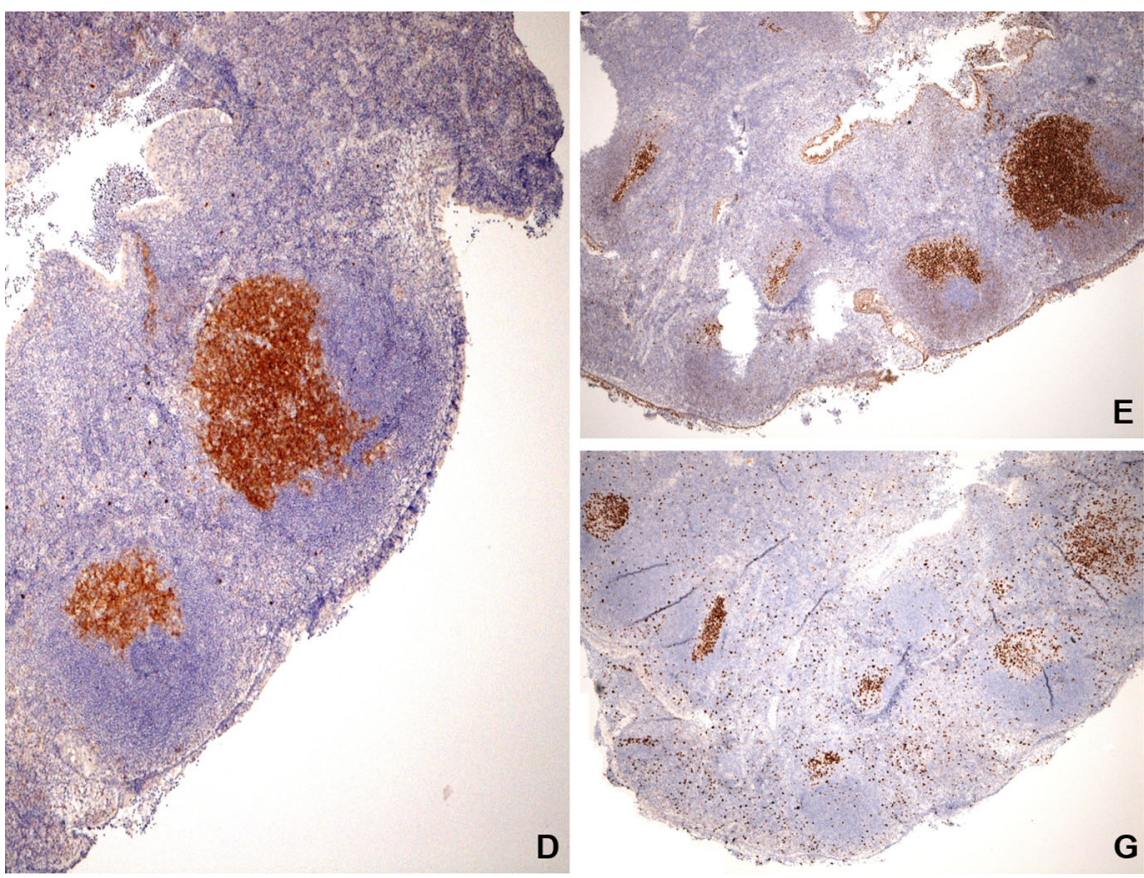

E

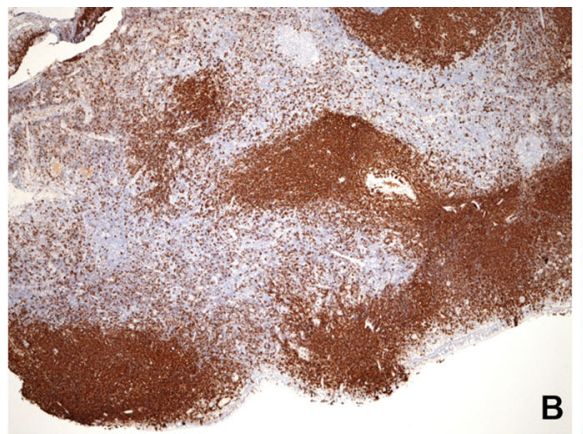

B
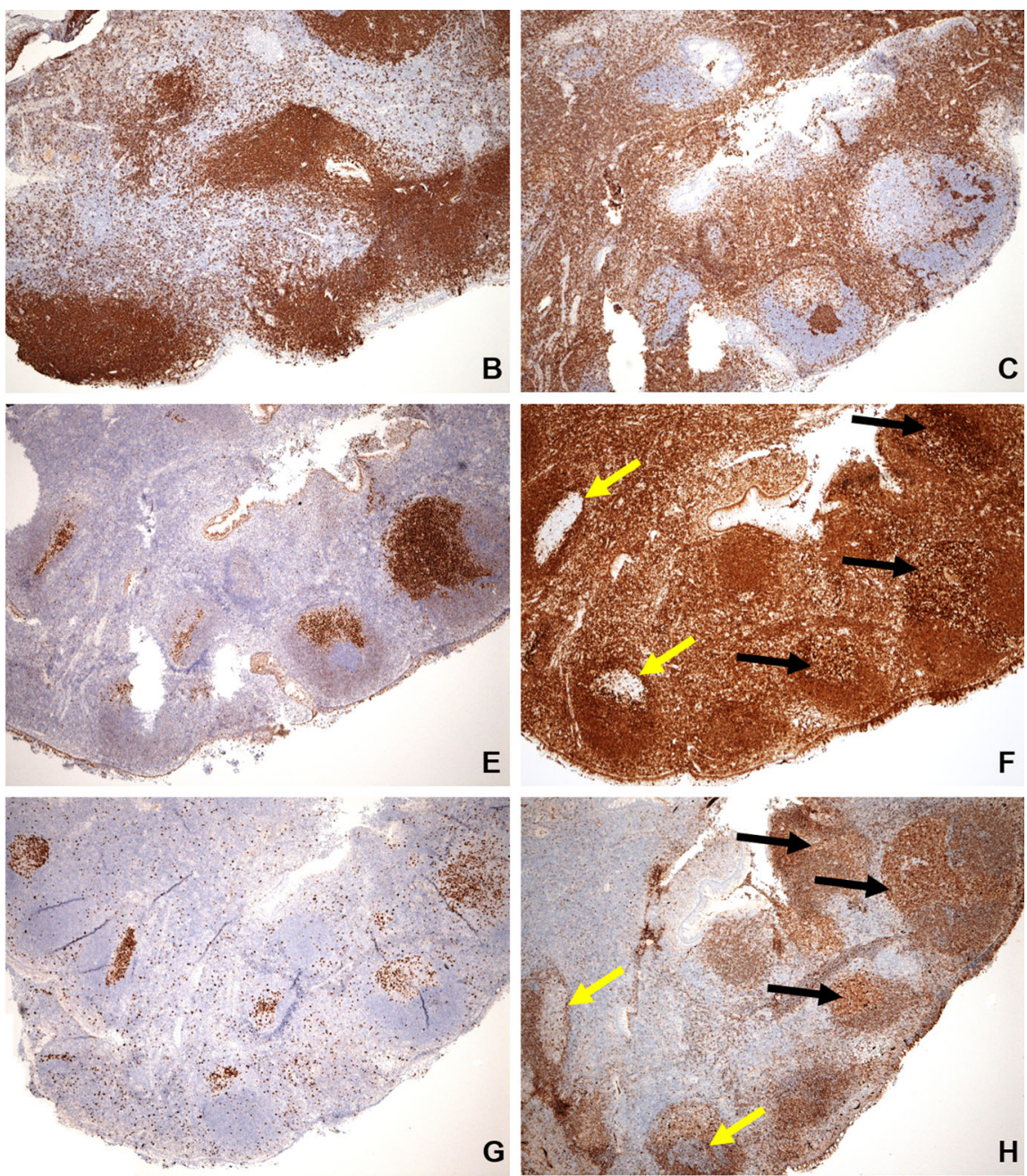

$\mathrm{F}$



Fig. 1 Ectopic tonsil (a, H\&E, 4×) partially involved by ISFN (b, CD20 clone L26, Ventana Roche, $4 \times$ ): the immunoreaction for CD3 discharges the possibility of enrichment of T cells in the germinal center (c, Ventana Roche, $4 \times$ ), while CD10 (d, Ventana Roche, 10×) and bcl6 (e, Ventana Roche, $4 \times$ ) rule out colonization by marginal cells. The neoplastic follicles immunohistochemically show a strong bcl-2 positivity (f, black arrows), which is contrariwise absent inside the reactive germinal centers (f, yellow arrows, Ventana Roche, $4 \times$ ). MIB1 labeling discloses a diffuse pattern in the neoplastic follicles and a polarized pattern in the reactive ones (g, Dako, $4 \times$ ). A monotypic expression for IgM has been detected only in the neoplastic germinal centers (h, black arrows), being absent in the non-neoplastic follicles (h, yellow arrows, Ventana Roche, $4 \times$ )

\section{Compliance with ethical standards}

Funding None.

Conflict of interest The authors declare that they have no competing interests.

\section{References}

1. Swerdlow SH, Campo E, Pileri SA, Harris NL, Stein H, Siebert R, Advani R, Ghielmini M, Salles GA, Zelenetz AD, Jaffe ES (2016) The 2016 revision of the World Health Organization classification of lymphoid neoplasms. Blood 127(20):2375-2390

2. Karnik T, Ozawa MG, Lefterova M, Luna-Fineman S, Alvarez E, Link M, Zehnder JL, Arber DA, Ohgami RS (2015) The utility of

IgM, CD21, HGAL and LMO2 in the diagnosis of pediatric follicular lymphoma. Hum Pathol 46(4):629-633

3. Zheng Y, Zhou X, Xie J, Zhu H, Zhang S, Zhang Y, Wei X, Yue B (2014) IgM expression in paraffin sections distinguishes follicular lymphoma from reactive follicular hyperplasia. Int J Clin Exp Pathol 7(6):3264-3271

4. Gru AA, Kreisel F, Duncavage E, Nguyen TT, Hassan A, Frater JL (2013) Acute EBV infection masquerading as "In-situ Follicular Lymphoma": a pitfall in the differential diagnosis of this entity. Diagn Pathol 8:100

5. Lee JC, Hoehn D, Schecter J, Murty VV, Mansukhani MM, Alobeid B, Bhagat G (2013) Lymphoid follicle colonization by Bcl-2(bright+)CD10(+) B-cells ("follicular lymphoma in situ") at nodal and extranodal sites can be a manifestation of follicular homing of lymphoma. Hum Pathol 44(7):1328-1340

6. Montes-Moreno S, Castro Y, Rodríguez-Pinilla SM, García JF, Mollejo M, Castillo ME, Bas-Vernal A, BarrionuevoCornejo C, Sanchez-Verde L, Menarguez J, Cigudosa JC, Piris MA (2010) Intrafollicular neoplasia/in situ follicular 
lymphoma: review of a series of 13 cases. Histopathology 56(5):658-662

7. Carbone A, Gloghini A (2014) Emerging issues after the recognition of in situ follicular lymphoma. Leuk Lymphoma 55(3): 482-490

8. Carbone A, Tibiletti MG, Canzonieri V, Rossi D, Perin T, Bernasconi B, Gloghini A (2012) In situ follicular lymphoma associated with nonlymphoid malignancies. Leuk Lymphoma 53(4):603-608

9. Cong P, Raffeld M, Teruya-Feldstein J, Sorbara L, Pittaluga S, Jaffe ES (2002) In situ localization of follicular lymphoma: description and analysis by laser capture microdissection. Blood 99(9): $3376-3382$ 